\title{
A PNEUMATOLOGIA DE VOLTAIRE E A INTERPRETAÇÃO DE ZADIG OU O DESTINO
}

\author{
Rodrigo Brandão ${ }^{1}$
}

Resumo: O presente artigo pretende distinguir em alguns textos de Voltaire duas categorias de personagens celestiais. A primeira se refere aos seres vindos do céu astronômico da ciência moderna. A segunda é composta pelos seres celestiais, os anjos e gênios que povoam os céus dos antigos, segundo o autor. Distinguir estas duas categorias nos serve aqui especialmente para fornecer uma intepretação de Zadig ou o destino e, por consequência, refletir sobre como o autor concebia a relação entre liberdade e providência.

Palavras-chave: Voltaire - seres celestiais - céu astronômico - céu dos antigos - Zadig - destino providência - liberdade.

(...)tous les philosophes qui ont voulu concilier les futurs contingents avec la prescience de Dieu ont été de bien mauvais négociateurs.

Voltaire a Frederico, 23 de jan. de 1738

A relação de Voltaire com a filosofia de Leibniz é bem mais complexa do que se poderia pensar a partir de uma ligeira leitura de um texto ligeiro como Cândido ou o otimismo. ${ }^{2}$ Embora realizado a partir de uma caricatura, o famoso conto de Voltaire toca em pontos sensíveis da filosofia do autor dos Ensaios de Teodiceia e da popularização da noção de melhor dos mundos possíveis ${ }^{3}$. Por sua vez, o conto publicado em 1747, cinco anos antes de Cândido, Zadig ou o destino, aborda outro tema filosófico caro tanto a Voltaire quanto a Leibniz. Em Zadig, no entanto, não encontramos explicitamente uma crítica ao pensamento de Leibniz sobre o destino, ou ao menos ela não é suficientemente nítida e sem hesitações como será em Cândido a respeito da noção de melhor dos mundos. Inicialmente concebido como Zadig ou a Providência, Voltaire opta pelo termo menos sacro e menos perigoso ${ }^{4}$. O conto de

\footnotetext{
${ }^{1}$ Professor do departamento de filosofia da Universidade Federal do Paraná (UFPR).

${ }^{2}$ Sobre as relações entre Voltaire e Leibniz e a recepção do pensamento do alemão pelo francês, ver: BROOKS, Voltaire and Leibniz; BARBER, Leibniz in France from Arnauld to Voltaire e BRANDÃO, A ordem do mundo e homem: estudos sobre metafisica e moral em Voltaire.

3 Sobre o tema, cf. BRANDÃO, Como levar Cândido a sério ou caricatura literária e crítica da teodiceia em Voltaire.

4 VAN DEN HEUVEL, Voltaire dans ses contes: de "Micromégas” à “L'ingénu”, p. 161.
} 
Voltaire dramatiza justamente suas dúvidas em torno dos temas do destino e da providência, objetos centrais das reflexões de Leibniz em seus Ensaios de Teodiceia e cujas relações organizam a distinção do autor entre três concepções de destino: o fatum stoïcum, o fatum mahometanum e o fatum christianum ${ }^{5}$.

A complexidade de Zadig só pode ser apreendida no contexto deste debate filosófico, e a moda literária dos contos orientais (cuja popularidade foi alimentada pela tradução e criação de Antoine Galland das Mil e uma noites, publicadas entre 1704 e 1717, e pelas Cartas Persas de Montesquieu, publicadas em 1721) serve ao autor como espaço literário privilegiado para a retomada deste debate filosófico e teológico. Voltaire dramatiza sua reflexão sobre o destino e a providência em um ambiente oriental, fazendo ecoar o suposto fatalismo de suas religiões. O autor introduz também uma série de lugares-comuns da tradição estoica ${ }^{6}$ e amalgama tudo com as referências de suas leituras de Leibniz e da Bíblia. Sem dúvida que o texto de Zadig marca na produção literária de Voltaire sua recepção do leibnizianismo, embora seu contato com o pensamento de Leibniz date ao menos dos anos 1737-38, em que discute a metafísica do alemão em sua correspondência com o ainda príncipe Frederico.

Entretanto, a reflexão sobre a filosofia de Leibniz e sua relação com as tradicionais questões do destino, da providência e das implicações morais do fatalismo no Zadigimplicaria em uma adesão às perspectivas do autor dos Ensaios de Teodiceia? Essa presença marcante da filosofia de Leibniz e o desenlace da narrativa, que mostra o personagem principal feliz após uma sequência de desventuras, seria motivo para afirmar uma adesão de Voltaire ao destino e à providência à la Leibniz? Ora, é isto o que pensam Paul Pelckmans e Jacques Van den Heuvel. ${ }^{7}$ Segundo os dois comentadores, a presença textual de perspectivas do filósofo alemão em personagens como o anjo Jesrad e o desenlace feliz da narrativa confirmam um Voltaire leibniziano, convencido da presença de uma providência que ao fim e ao cabo organiza para o bem (ou o maior bem possível) o aparente caos da vida humana. Dentro disso, gostaria particularmente de mostrar a dificuldade ou impossibilidade de identificar a voz de Voltaire com a do anjo Jesrad como faz Van den Heuvel. ${ }^{8}$ Ele chega mesmo a dividir o conto em duas partes: a primeira em que o personagem Zadig é porta-voz de Voltaire, e a segunda, em que o autor faria de Jesrad seu novo porta-voz. O presente artigo reconhece certamente o pano de fundo leibniziano sobre o qual se desenrola o conto, e até mesmo a presença de uma tentação leibniziana por assim dizer. No entanto, pretende-se mostrar os obstáculos a esta interpretação da mensagem do conto, ou seja, apresentando um Voltaire hesitante em relação à questão do destino e da providência e desconfiado da mensagem moral do leibnizianismo.

5 LEIBNIZ, Essais de Théodicée, pp. 30-31.

6 Sobre o tema, ver: ROVILLAIN, Rapports probables entre Zadig de Voltaire et la Pensée Stoïcienne.

7 PELCKMANS, Le problème de l'incroyance au XVIIIe siècle e VAN DEN HEUVEL, Voltaire dans ses contes: de "Micromégas" à "L'ingénu".

8 De resto, cabe dizer que de maneira geral, e em particular nos textos sobre a providência, temos de ter cuidado em não identificar apressadamente a voz de Voltaire com a de seus personagens. No diálogo "Providência", que aparece nas Questões sobre a Enciclopédia em 1771, por exemplo, embora claramente não possamos identificar a voz de Voltaire com a da freira, tampouco podemos identificar completamente sua voz com a do metafísico, do qual o autor se vale para criticar a personagem religiosa. 


\section{Os seres celestiais}

Em muitas de suas obras, Voltaire se vale de personagens celestiais. Basta lembrar alguns famosos, sem intenção exaustiva. Além do anjo Jesrad, de Zadig ou o destino, Micrômegas e o saturniano, de Micrômegas uma história filosófica, o gigante de outro planeta que faz pela primeira vez a experiência de conhecer a Terra e os homens, do Tratado de Metafísica, o anjo que aparece ao personagem principal de Memnom ou a sabedoria bumana e aquele que alça o velho chinês aos céus, no sexto discurso do Discursos em versos sobre o homem.

Os personagens celestiais devem, no entanto, ser distinguidos em duas categorias com valores diferentes e com papéis distintos dentro dos objetivos do autor. Não basta dizer que eles visam apenas realizar literariamente o dépaysément, a experiência de deslocamento do ponto de vista. $\mathrm{Na}$ verdade, é preciso sublinhar a diferença entre eles, pois pensar que Micrômegas e Jesrad cumprem a mesma função nos contos de Voltaire leva a confundir as vozes filosóficas que estão por trás do expediente literário. Trata-se, portanto, do mesmo expediente que se vale de figuras variadas para cumprir exigências filosóficas distintas. É certo que realizam aquele olhar distanciado que permite relativizar os pequenos problemas da vida perante a imensidão do universo, aquele olhar desde o alto, como bem descreveu Pierre Hadot ${ }^{9}$. Entretanto, os diferentes personagens pretendem causar efeitos divergentes em seus leitores, e o olhar do alto pode tanto representar o distanciamento sadio que o filosofo deve ter para bem compreender as coisas do mundo que de outra forma estão sempre muito próximas quanto ser a alegoria de uma figura com a cabeça nas nuvens um tanto ridícula.

Dentre os seres celestiais, há os extraterrestres, os seres de outros planetas como Micrômegas, o saturniano e aquele ser "vindo de Marte ou Júpiter", do Tratado de Metafísica, e há os anjos, os seres incorpóreos como Jesrad, o gênio que aparece a Memnom e o anjo do sexto discurso, do Discurso em versos sobre o homem. Como veremos, estes dois conjuntos de figuras não têm a mesma função e não desempenham o mesmo papel de dramatização filosófica no conjunto dos textos de Voltaire, nem habitam o mesmo céu. Considerar a singularidade de cada uma dessas categorias de seres celestiais tem diversos resultados para a compreensão das obras de Voltaire. Aqui a distinção entre o céu dos antigos e o céu dos modernos, entre heaven e skey, para retomar a fórmula de Alexander Koyrè ${ }^{10}$, e seus respectivos habitantes nos ajudará a interpretar o sentido de Zadig ou o destino.

\section{Os extraterrestres empiristas}

$\mathrm{Na}$ introdução do Tratado de Metafísica, o gigante de outro planeta que desce à Terra é um expediente que visa cumprir uma exigência encontrada na filosofia de Locke. O conhecimento do homem, objetivo da investigação do Tratado de Voltaire, só pode ser realizado por meio da observação. Mas a experiência de ver a si mesmo não é simples ${ }^{11}$. É

\footnotetext{
${ }^{9}$ HADOT, N'oublie pas de vivre. Goethe et la tradition des exercices spirituels, pp. 87-162.

10 KOYRÉ, From the closed world to the infinite universe.

11 "The understanding, like the eye, whilst it makes us see and perceive all other things, takes no notice of itself; and it requires art and pains to set it at a distance, and make it its own object". (LOCKE, J. An Essay Concerning Human Understanding, p. 11).
} 
preciso despojar-se "de todos os preconceitos de educação, de pátria e, sobretudo, dos preconceitos de filósofo"12. A experiência para ser válida tem de ser feita após um afastamento das circunstâncias que perfazem o observador, daí o recurso a um personagem não imerso naquilo mesmo que é objeto da observação; esse personagem condensa o movimento de distanciamento que "requer arte e esforço"

Além de artifício de distanciamento e de preparação para a observação, a figura do gigante permite a Voltaire dramatizar aquilo que chamava de análise, o procedimento de observação e organização dos dados da experiência que avança lentamente em direção às leis da natureza e aos princípios, à diferença, segundo o autor, do método geométrico em filosofia. As aquisições do gigante de outra estrela do Tratado de Metafísica vão sendo progressivamente superadas por novas e mais precisas observações. O mesmo procedimento aparece em Micrômegas: os personagens extraterrestres vão progressivamente conhecendo a Terra e os seres que nela habitam por meio de um processo de erro e acerto. As observações que o saturniano faz sobre o comportamento dos homens logo são superadas por novas e mais precisas observações, bem como as considerações que o gigante do Tratado faz sobre o que considera ser o animal racional se modificam a partir do contato com a diversidade de homens.

Micrômegas cumpre essa exigência de afastamento da condição de homem e de dramatização da análise, além de estabelecer outras relações interessantes com o que Voltaire chamava de filosofia experimental. A sabedoria de Micrômegas é proporcional aos seus sentidos (ele tem mais de mil) e à sua longevidade (apesar de ser apenas um jovem de 350 anos, segundo o autor), sua experiência e sua capacidade de acessar outros níveis da realidade por meio de seus variados sentidos constituem a sua grandeza de espírito e alimentam a imaginação literária. Além disso, Micrômegas e o saturniano viajam pelo universo graças aos seus conhecimentos da física newtoniana. Não há naves espaciais, nada de tecnologia. É um rabo de cometa ou "as forças atrativas e repulsivas" 14 que fazem os viajantes percorrerem diversos globos "como um pássaro voeja de ramo em ramo" ${ }^{15}$. Mais ainda, os seres de outro planeta, os seres do céu astronômico por assim dizer, agem filosoficamente observando o procedimento experimental de Locke. No final das contas, os extraterrestres das obras de Voltaire são empiristas, daí a simpatia do gigante de Micrômegas pelo seguidor de Locke, eles observam, aprendem com a experiência, duvidam e não fazem sistemas, reconhecem, enfim, os limites do entendimento humano. Esses extraterrestres não são alienígenas, não são estranhos, têm olhos, corpo, são na verdade apenas maiores e mais sábios ${ }^{16}$. Conhecem à proporção de seus sentidos e a eles também são limitados, pois também só podem apresentar um livro em branco quando se trata de metafísica. Portanto, partilham com os homens a

12 VOLTAIRE, Tratado de Metafisica, p. 61.

${ }^{13}$ LOCKE, An Essay Concerning Human Understanding, p. 11.

${ }^{14}$ VOLTAIRE, "Micrômegas, uma história filosófica". In: Contos, p. 114.

15 Idem.

16 A primeira redação da carta sobre Locke das Cartas Inglesas, a chamada Carta sobre a alma, já contém uma referência ao seres de outros planetas dotados de mais sentidos: "Il y a beaucoup d'animaux qui n'ont que deux sens; nous en avons cinq, ce qui est bien peu de chose; il est à croire qu'il est dans d'autres mondes d'autres animaux qui jouissent de vingt ou trente sens, et que d'autres espèces, encore plus parfaites, ont des sens à l'infini”". VOLTAIRE, "Lettre sur l'âme". In: Mélanges, p. 46. 
mesma condição: ignorância a respeito daquilo que extrapola os limites da observação. Enfim, aquilo que conhecem, os homens também podem conhecer. Somos em certa medida uma mistura de grandeza e pequenez, certezas (pois não nos esqueçamos que não há dúvida ou diafonia quando se fala sobre a luz e os astros e sobre o tamanho da Terra) e dúvidas, somos todos micro e mega, eis o sentido do nome do personagem principal do conto, grandeza quando nosso conhecimento se refere ao mundo observável e ignorância quando este limite não é respeitado.

\section{A pneumatologia de Voltaire}

Já os seres do céu teológico por assim dizer, os anjos e gênios, desempenham outro papel no conjunto dos textos de Voltaire e se relacionam a outras posições filosóficas. Os seres incorpóreos têm valor distinto daquele dos extraterrestres, cumprem o papel de mensageiros do sistema do otimismo filosófico, sempre estão encarregados de apresentar a visão do encadeamento do todo, da proporção e da ordem, enfim, eles são responsáveis pela adoção daquilo que Pomeau chamou de ponto de vista teocêntrico. Voltaire tem uma fascinação por tais seres. O autor lhes dedica vários verbetes intitulados "Ange": na obra L'Opinion en Alphabet, de 1752, no Dicionário Filosófico, de 1764, e nas Questões sobre a Enciclopédia, de 1772. Com eles Voltaire elabora uma breve história dos pneuma, dos seres incorpóreos encarregados de fazer a ligação entre o divino e o humano. De acordo com o autor, os anjos e gênios são muito antigos e estão presentes em quase todos os povos da Antiguidade, são ainda mais antigos que a concepção da imortalidade da alma ${ }^{17}$. Amparado nos trabalhos sobre as religiões orientais realizados pelos ingleses (Holwell sobre os brâmanes, Sale com a tradução do Alcorão e Hyde sobre a religião dos persas), Voltaire fornece exemplos dos antigos povos do Oriente e suas respectivas figuras celestiais.

Consideremos duas outras aparições de anjos e gênios, além daquela de Jesrad, para compreendermos o significado da distância entre eles e os homens. Memnom ou la sagesse bumaine tem também uma aparição de um anjo mensageiro da providência. O personagem principal desse conto oriental, Memnon, ignorante da limitação humana, "concebeu um dia o insensato projeto de ser perfeitamente sábio"18. Decidiu então que deveria se privar do amor das mulheres, dos prazeres da boa mesa e do vinho, deveria também garantir sua independência financeira para jamais ter a "cruel necessidade de frequentar a corte" ${ }^{19} \mathrm{e}$, por

17 A imortalidade da alma era, para Voltaire, uma noção que provavelmente levou muito tempo para se estabelecer entre os homens, pois ela exige uma abstração e outras sutilezas metafísicas que não estariam presentes nos povos mais recuados no tempo, de acordo com o autor. Nesse sentido, comparadas as noções dos seres incorpóreos e a da imortalidade da alma é possível reconhecer que os anjos e os gênios pertencem a um tempo ainda mais afastado, ainda mais fantasioso. "La doctrine des anges est une des plus anciennes du monde, elle a précédé celle de l'immortalité de l'âme: cela n'est pas étrange. Il faut de la philosophie pour croire immortelle l'âme de l'homme mortel: il ne faut que de l'imagination et de la faiblesse pour inventer des êtres supérieurs à nous, qui nous protègent ou qui nous persécutent". (VOLTAIRE, "L'Opinion en Alphabet". In: Oeuvres complètes de Voltaire) 18 VOLTAIRE, "Memnon, ou a sabedoria humana". In: Contos, p. 103.

${ }^{19}$ Os anos em torno da redação de Zadig e Memnom marcam em Voltaire uma crítica à vida cortesã. Para Pomeau, Zadig chega a ser até mesmo um "anti-Versailles", em referência ao seu poema laudatório da vida cortesã, La vie en Versailles. Mais importante é que nestes anos Voltaire reconsiderará certas 
fim, conservar seus amigos. Após ter concebido todo este plano no isolamento de seu quarto, Memnon olha pela janela que lhe apresentará o mundo e a vaidade de seus projetos. Logo se condói de uma bela moça que vê chorar e decide ter com ela. Ela o convence a segui-la até a casa de seu tio. Lá, Memnon, desejando ajudar uma figura "tão honesta e tão desgraçada"20, acaba por se entreter com a moça a tal ponto que ambos "não sabiam mais onde se achavam" "21. Flagrado pelo tio da pobre criatura, Memnon escapa a punição maior mediante a entrega de tudo que trazia consigo. Triste e abalado, mais por ter cedido à tentação da carne do que por ter perdido a módica quantia que trazia consigo, Memnon volta para casa e lê um bilhete dos amigos que lhe convidam para um jantar. Memnon para lá se dirige com o intuito de fazer uma refeição frugal e se divertir com os amigos, buscando alívio para a tristeza do dia. Então se embriaga, joga, perde dinheiro e entra em uma disputa que lhe resulta em um olho vazado por um copo de dados lançado em seu rosto. Devendo dinheiro e caolho, ele se dirige a corte para pedir auxílio ao rei e de lá logo sai para não perder o olho que lhe restava. Ao voltar para casa, Memnon encontra oficiais que lhe despejam e é visto triste e caolho pela moça e o tio, que dele zombam. Deita-se junto ao muro de sua casa e dorme febril. No seu sonho um espírito celeste com "seis belas asas mas, sem pés, nem cabeça, nem cauda, e que não se assemelhava a coisa alguma" 22 , surge e trata de lhe apresentar a organização do todo. $\mathrm{O}$ anjo afirma que Assan, irmão de Memnon, era mais digno de lástima do que ele. Assan perdera os dois olhos e encontrava-se preso. Memnon então pergunta ao gênio celeste:

- Mas que adianta ter um gênio na família, para que, de dois irmãos, um esteja caolho, o outro cego, um nas palhas, outro na prisão? (VOLTAIRE, "Memnon ou a sabedoria humana". In: Contos, p. 107).

O anjo então lhe assegura que ainda será um caolho bem feliz, "contanto que não faça o tolo projeto de ser perfeitamente sábio" ${ }^{23}$. Memnon, então pergunta ao anjo se isso é algo impossível, ao que o anjo responde:

- Tão impossível como ser perfeitamente hábil, perfeitamente forte, perfeitamente poderoso, perfeitamente feliz. Nós próprios estamos muito longe disso. Há um globo em tais condições; mas, nos cem milhões de mundos que estão esparsos pela imensidade, tudo se encadeia por gradações. Tem-se menos sabedoria e prazer no segundo que no primeiro, menos no terceiro que no segundo. E assim até o último, onde todos são completamente loucos. (VOLTAIRE, "Memnon ou a sabedoria humana". In: Contos, p. 107).

posições afirmadas em textos anteriores como Le mondain e a vigésima quinta carta sobre Pascal, nas Cartas Filosóficas. Sobre a crítica a esta vida que os tempos da França do XVIII podiam proporcionar e a ligação entre o tédio e o divertimento ver: POMEAU, La Religion de Voltaire, pp. 240-250.

20 VOLTAIRE, “Memnon ou a sabedoria humana". In: Contos, p. 104.

${ }^{21}$ Idem, p. 104.

22 Grifo nosso.

${ }^{23}$ VOLTAIRE, "Memnon ou a sabedoria humana”. In: Contos, p. 107. 
- Receio muito - disse Memnon - que este nosso pequeno globo terráqueo seja precisamente o hospício do universo de que me fazes a honra de falar.

Não tanto - respondeu o espírito -, mas aproxima-se: tudo está no seu lugar. Ah! - exclamou Memnon - Bem se vê que certos poetas, certos filósofos, não têm razão nenhuma em dizer que tudo está bem.

Pelo contrário, têm toda a razão - retrucou o filósofo das alturas -, levandose em conta o arranjo do universo inteiro.

Ah! só acreditarei nisso - replicou o pobre Memnon - quando não for mais caolho. (VOLTAIRE, “Memnon ou a sabedoria humana”. In: Contos, p. 107).

Não podemos perder de vista que todo esse relato sobre as intenções de Memnom e o que lhe acontece no mundo real constituem uma crítica ao rigorismo moral. Para Voltaire, as virtudes ascéticas não são propriamente virtudes. De acordo com nosso autor, somente as atitudes que se relacionam com o outro, somente as virtudes sociais podem ser ditas propriamente virtudes, caso contrário os homens virtuosos se pareceriam todos com aquele faquir das Cartas de um Turco sobre os faquires e seu amigo Bababec, cuja felicidade última se traduzia em não enxergar nada além da ponta de seu nariz. A reativação de categorias antigas no mundo em que vive nosso autor lhe aparece apenas como a recusa da vida em comum e da benevolência. A definição voltairiana da virtude como comércio de benefícios não concebe valor algum nas virtudes que são apenas individuais. Entretanto, o que nos interessa destacar aqui é outro aspecto, aquilo que vem desvelar o verdadeiro valor destas figuras celestiais, dos mensageiros dos céus, os anjos e gênios.

Memnom guarda para si principalmente a imagem do caos da vida humana, do "hospício do universo" que é a Terra. Para ele, da perspectiva parcial que é a sua, o lema popiano whatever is, is right não faz sentido. Mas o anjo lhe explica a verdade profunda do otimismo filosófico: para que ultrapassemos a visão caótica da vida humana e as lamentações que decorrem dessa miopia da parte é preciso considerar "o arranjo do universo inteiro". É ao considerar, a partir da perspectiva do todo, que o homem é apenas um pequeno elemento de um universo vasto e variado, reconheceremos a verdade do otimismo filosófico. Contudo, Memnom também não se convence e contra a exigência da perspectiva global, da perspectiva teocêntrica, Menmon opõe o ponto de vista humano e parcial. O lema tudo está bem quer relativizar o mal e consolar o homem, mas o homem, incapaz de abandonar sua posição, não se consola perante a proporção da vasta cadeia do ser. Como dirá nosso autor, a filosofia esclarece, mas não consola.

Qual é, portanto, a sabedoria humana? O tudo está certo da filosofia de Pope? É possível aos homens acreditarem naquela gradação do universo apresentada pelo anjo no sonho febril de Memnon? Não, a sabedoria humana não consiste no otimismo. Ela é, na verdade, a tomada de consciência da limitação da condição humana, a sabedoria própria ao homem é o conhecimento do seu caráter limitado e imperfeito. O homem perante a teoria exposta pelo "filósofo das alturas" não pode senão desconfiar. Guardadas algumas diferenças, como o fato de neste conto o protagonista ter a última palavra e não o anjo, as atitudes de Zadig e Menmon perante os seres incorpóreos são muito semelhantes. A contemplação da ordem do todo não consola o homem que sofre, porque, após o esforço 
intelectual que ela exige, o retorno à condição de homem é o retorno aos sentidos, ao seu testemunho pessoal e ao sofrimento. Memnom escuta o anjo, compreende a ordenação que lhe é apresentada, mas de volta a si continua a ser caolho e a sofrer, a partir de sua posição não lhe resta senão desconfiar das palavras do gênio. Esta desconfiança e esta impossibilidade de satisfazer os anseios do homem já estavam presentes no apólogo do velho chinês rezingão, no sexto discurso dos Discurso em versos sobre o homem (1961).

O sexto discurso dos Discurso em versos sobre o homem é um texto marcado pela leitura do An Essay on Man de Pope. O poeta inglês e Leibniz são chamados para enfrentar a sátira da natureza humana feita por Pascal. Mas se perante Pascal o otimismo filosófico é um "sage milieu", a "cadeia invisível" permanece "escondida"24. Voltaire confessa que a "vasta ciência" ou o ultrapassa ou o faz calar ${ }^{25}$. O "compasso francês" que lhe impede de ter a liberdade dos gregos e dos ingleses conduz o autor a narrar um "récit veritable" ${ }^{26}$; impossibilitado que está em tomar partido da discussão em nível meramente teórico, ele dramatiza os problemas com os quais lida o otimismo filosófico. Trata-se de uma história oriental que contém diversas criaturas que se gabam de ser a obra-prima da criação, até a voz do Deus chinês reuni-las (anjos, homens, quadrúpedes e seres diversos) e lhes dizer que tudo é o que deve ser, que são todos instrumentos imperfeitos de um todo perfeito e que todos devem permanecer satisfeitos, cada qual em sua condição ${ }^{27}$.

Eis uma vez mais o ponto de vista teocêntrico, o próprio Deus vem criticar o orgulho das criaturas que se consideram a obra-prima e o centro do universo, exigir que se reconheça

24 "Montre l'homme à mes yeux: honteux de m'ignorer,

Dans mon être, dans moi, je cherche à pénétrer,

Despréaux et Pascal en ont fait la satire;

Pope et le grand Leibnitz, moins enclins à médire,

Semblent dans leurs écrits prendre un sage milieu;

Ils descendent à l'homme, ils s'élèvent à Dieu:

(...)

Montre-moi, si tu peux, cette chaine invisible

Du monde des esprits et du monde sensible;

Cet ordre si caché de tant d'êtres divers,

Que Pope après Platon crut voir dans l'univers".

(VOLTAIRE, "Discours en vers sur l'homme". In: Mélanges, p. 231).

25 "Vous me pressez en vain; cette vaste science,

Ou passe ma portée, ou me force au silence.

Mon esprit, resserré sous le compas français,

N'a point la liberté des Grecs et des Anglais.

Pope a droit de tout dire, et moi je dois me taire". (Idem, ibidem, p. 231-232).

${ }^{26}$ É importante perceber nas citações das duas notas anteriores que Voltaire reconhecia desde seu

Discurso em versos sobre o homem, de 1738-42, a paternidade grega da noção de chain of being tão cara ao otimismo filosófico inglês de Pope, Bolingbroke e Shaftesbury. Esta origem o autor voltará a explorar no verbete "Bem (tudo está)", do Dicionário filosófico, de 1764.

27 "Vous êtes nés pour moi, rien ne fut fait pour vous:

Je suis le centre unique où vous répondez tous.

Des destins et des temps connaissez le seul maittre.

Rien n'est grand ni petit; tout est ce qu'il doit être.

D'un parfait assemblage instruments imparfaits,

Dans votre rang placés demeurez satisfaits". (Idem, ibidem, p. 233). 
a ordem perfeita e se interrompam as lamentações. Deus governa os destinos visando sempre um todo perfeito, e o todo perfeito se vale da existência de partes imperfeitas. A compreensão da relação entre a "parfait assemblage" e os "instruments imparfaits" deveria emudecer os lamuriosos, pois não há pequenez propriamente dita, apenas adequação e proporção. Mas havia por ali um velho culto que expõe seus lamentos, mostrando sua insatisfação com as limitações humanas de todo tipo ${ }^{28}$. Para convencer o velho chinês rezingão da ordem e proporção do universo, um anjo o leva até os céus. Ele pode, então, contemplar o universo de uma posição mais próxima daquela do criador, mas ele ainda reluta em aceitar, e é forçado a concluir que no universo cada ser tem sua medida e que devemos nos submeter à lei que não podemos corrigir ${ }^{29}$.

Uma vez mais a "medida" de cada ser visa a denunciar a desmedida dos desejos humanos. A ordenação do universo guarda um lugar fixo, limitado e necessário ao homem, daí a inutilidade das preces a um Deus que não muda a ordem do todo para atender os anseios de uma pequena parte. $\mathrm{O}$ velho chinês parece aceitar temporariamente a ordenação do todo, que por sua vez deveria conduzir à atitude moral de submissão à "lei que não se pode corrigir”. Todavia, o reconhecimento da ordem e o sentimento de aceitação que dele se segue só duram o tempo em que o velho permanece nos céus, de volta à Terra, ele confessa que é difícil convencê-lo. Certamente está em jogo aqui a imagem do doutor convicto que não se permite mudar de ideia, mas ao que tudo indica somos todos um pouco este velho rezingão, de volta aos nossos corações passamos a dar valor aos sofrimentos particulares, e o ponto de vista geral pouco tem a consolar. A aceitação da mensagem do otimismo só dura o tempo em que realizamos a abstração de nos alçarmos às esferas celestiais, novamente na condição de homem, nossos sofrimentos e nossas lamentações suplantam toda a imagem de adequação e proporção que a cadeia dos seres poderia oferecer. Não há como salvaguardar a mensagem de submissão que a perspectiva global pretendia exigir. Este é o ponto fraco do otimismo filosófico: embora racionalmente seja possível se convencer da ordem e da proporção, o

28 "Pourquoi suis-je en un point resserré par le temps?

Mes jours devraient aller par delà vingt mille ans;

Ma taille pour le moins dut avoir cent coudées;

D'où vient que je ne puis, plus prompt que mes idées,

Voyager dans la lune, et réformer son cours?

Pourquoi faut-il dormir un grand tiers de mes jours?

Pourquoi ne puis-je, au gré de ma pudique flamme,

Faire au moins en trois mois cent enfants à ma femme?

Pourquoi fus-je en un jour si las de ses attraits?" (VOLTAIRE, "Discours en vers sur l'homme". In:

Mélanges, p. 233).

29 "Le Chinois argumente: on le force à conclure

Que dans tout l'univers chaque être a sa mesure;

Que l'homme n'est point fait pour ces vastes désirs;

Que sa vie est bornée ainsi que ses plaisirs;

Que le travail, les maux, la mort sont nécessaires;

Et que, sans fatiguer par de lâches prières

La volonté d'un Dieu qui ne saurait changer,

On doit subir la loi qu'on ne peut corriger". (Idem, ibidem, p. 234). 
otimismo falha ao tentar retirar da contemplação racional da ordem uma mensagem moral e uma orientação prática.

A mensagem do ser incorpóreo revela novamente uma distância entre a sabedoria dos céus e os anseios da parte. É certo que ela poderia representar a inadequação destes anseios, mas a permanência da perspectiva parcial ressalta que esta condição é insuperável, e acentua a impossibilidade de se extrair uma mensagem moral que considere apenas meio homem, que não fale ao coração. Portanto, não é muito difícil ver que os anjos e gênios são porta-vozes de uma sabedoria sobrenatural, estão encarregados de apresentar aquilo que os homens por eles mesmos seriam incapazes de conhecer. Neste sentido, as figuras dos anjos e gênios de que tratamos tem duas funções. Por um lado, ao apresentar a visão do otimismo filosófico, eles representam o esforço de abstração necessário a esta concepção, o abandono dos sentidos e a tomada do ponto de vista teocêntrico, global, e, ao mesmo tempo, marcam o caráter inacessível, o teor sobrenatural e fantasioso do discurso otimista certo de si mesmo. No final das contas, não se pode permanecer na perspectiva teocêntrica. O homem é mesmo esta oscilação entre o polo em que contempla a ordenação, um ponto de vista racional, e aquele em que está ele próprio imerso, composto pelo caos e pelo sofrimento. Além disso, assimilar o discurso do otimismo filosófico, de autores modernos como Leibniz e Pope, às narrativas antigas, ao oriente fantasioso e à Bíblia reforça a precaução que se deve tomar em relação a mensagem dessas filosofias.

Estamos convencidos, portanto, que Zadig não representa a adesão ao otimismo filosófico, mas se trata antes da apresentação e dramatização das dúvidas do próprio autor. Ao invés de uma submissão à ordenação e proporção do universo e sua consequente interdição do lamento, Zadig é a forma ficcional das aproximações e dos distanciamentos de Voltaire em relação ao otimismo, neste caso sobretudo o de Leibniz. Zadig vem tornar mais nítido algo que já estava presente no Discurso em versos sobre o homem, a oposição entre o ponto de vista humano e o ponto de vista divino, aquele exigido pelo otimismo filosófico. Essa tensão se traduzia na atitude de insatisfação do homem perante a mensagem da providência, representado pela figura do velho chinês. Aquilo que no Discurso era a imagem de um velho recalcitrante, que não se deixa convencer, reaparece em Zadig e Memnom, com a diferença que em Memnon a ideia de que a parte não se consola perante a ordenação é ainda mais forte, e Zadig já retomara esta imagem e identificara o ponto de vista teocêntrico a um esforço de abandono da condição particular, esforço que não pode ser permanente, se é que realizável.

Os anjos e gênios que povoam os textos de Voltaire, por mais que sejam mensageiros de perspectivas que verdadeiramente atraíam a atenção e incitavam a curiosidade do philosophe, sempre trazem consigo a hesitação e a desconfiança que se deve ter com as sabedorias orientais e com a antiguidade, estão sempre relacionados com o fantasioso, com o maravilhoso que Voltaire, utilizando esse recurso, não deixou de criticar. O próprio Jacques Van den Heuvel reconhece e explora esta ambiguidade do maravilhoso na obra de Voltaire ${ }^{30}$.

30 “Au moment même où il découvre dans l'Orient le berceau de la sagesse et le foyer de toutes lumières, Voltaire continue à railler ses imaginations déréglées et ses folles métaphores: 'Il semble que dans ces pays on n'ait presque jamais parlé que pour ne pas être entendu...'. En particulier, il ne manque pas de faire appel à l'expression péjorative de 'contes des Mille et Une Nuits' lorsqu'il veut dénoncer quelque monstrueuse absurdité". (VAN DEN HEUVEL, Voltaire dans ses contes: de "Micromégas" à "L'ingénu”, p. 183). 
Embora a “aversão" de Voltaire ao fabuloso não impeça que ele utilize inteligentemente esse recurso romanesco, em seu caráter filosófico devemos reconhecer que ele remete a um tempo supersticioso e a uma sabedoria sobrenatural. O uso pejorativo de termos como romance, fábula, conto de Mil e Uma Noites é recorrente quando Voltaire quer criticar o espírito de sistema de Descartes e outros. Da mesma maneira, o uso de anjos e gênios para transmitir a mensagem otimista, bem como a atmosfera oriental como um todo, quer ressaltar a inverossimilhança presente nesse sistema, a distância entre a sabedoria professada e as capacidades humanas. Poderíamos dizer que aqueles anjos e gênios vêm do céu dos antigos, e não do céu do "verdadeiro sistema do mundo", em expressão de Voltaire. Os extraterrestres fazem parte do céu astronômico e pertencem a um universo newtoniano, já os anjos ainda pertencem a um tempo supersticioso em que entidades celestiais incorpóreas regiam a vida dos homens.

Este sentido é corroborado pela leitura dos verbetes "Ciel des anciens" e "Ciel matériel" das Questões sobre a Enciclopédia (1772). O que distingue esses dois céus? Enquanto os antigos tinham uma "física de crianças e velhos", que fazia seus deuses habitarem planetas e estrelas como os senhores habitavam cidadelas nas montanhas, o "verdadeiro sistema do mundo" nos mostra o céu real, em que não há propriamente "nem acima nem abaixo" e tudo é regido por uma "gravitação eterna". Aqui vemos que a compreensão voltairiana do processo de homogeneização do universo realizado pela ciência moderna já estava condensado na composição literária e na criação de suas personagens.

O que nos interessa sublinhar, portanto, é o caráter sobrenatural dos anjos e gênios. Intermediárias entre o divino e o humano, estas personagens são mensageiras de uma esfera distante do homem, falam de um saber normalmente vedado às capacidades humanas, e fazem parte de um tempo de superstição e fantasia. Diferentemente dos extraterrestres, que só se distinguem dos homens em suas proporções, os seres espirituais são totalmente estranhos. São seres sem "pés, nem cabeça", não se assemelham a nada, dirá Voltaire sobre o anjo que aparece a Memnom. São gênios, anjos, mensageiros de uma esfera tão distante, que não podemos deixar de perceber que o saber que professam escapa ao homem.

\section{Considerações finais}

Para reforçar ainda mais nossa conclusão a respeito da interpretação de Zadig e da atitude de Voltaire em relação à providência, restaria perguntar, como faz Pomeau, se o final feliz do conto é realmente o fim da história ${ }^{31}$. Para Van den Heuvel, a estrutura do conto com o seu desenlace feliz espelha a ação providencial. Mas notemos que não há um "felizes para sempre”. Zadig rei e feliz com seu amor, mas até quando? Será que amanhã Zadig não

\footnotetext{
31 “Tout est pour le mieux dans le meilleur des mondes, provisoirement. Car cela durera-t-il ? La fin du récit est-elle une 'fin de l'Histoire', établissant un bon ordre immuable ? On ne peut le croire. 'Le plus beau siècle de la terre' n'a qu'un temps: l'auteur, comme les lecteurs du Siècle de Lonis XIV le savent bien. Des grains de sable vont s'introduire dans un si bel ordre, comme ils ont déréglé le cours heureux du ministère de Zadig sous le règne de Moabdar. Et l'amour parfait des deux amants royaux sera-t-il éternel? Après 'la lune de miel', viendra inévitablement 'la lune de l'absinthe'. Telle est la triste réalité, comme l'atteste, non seulement 'le livre du Zend', mais l'expérience banale de la vie (chapitre III)". (POMEAU, "Introduction". In: VOLTAIRE, Micromegas, Zadig, Candide, p. 27).
} 
sofrerá novamente as desilusões do amor e as intrigas da corte? Van den Heuvel não se lembra que quando se fala em felicidade, é preciso considerar a máxima antiga de acordo com a qual só é possível atribuir felicidade a uma vida após o seu fim. Isto é reforçado por uma nota final ao Zadig, lembrada pelo próprio Jacques Van den Heuvel, que afirma que as aventuras de Zadig continuam ${ }^{32}$.

Sem dúvida, comparado ao Cândido, Zadig está mais próximo do otimismo de Leibniz e Pope, pois, além da presença de um plano providencial em Zadig e de sua ausência em $\operatorname{Candido}^{33}$, os personagens encarregados de encarnar a mensagem otimista em cada conto têm valores diferentes. Enquanto Pangloss é risível aos olhos do leitor, Jesrad desperta o sentimento ambíguo de respeito e desconfiança. Em Zadig, Voltaire parece tentado pelo otimismo, mas mantém suas dúvidas e hesitações. No Cândido, por sua vez, reconhecemos um afastamento completo do otimismo filosófico, justamente pela ausência do nível providencial na narrativa. A passagem de uma posição a outra não se dá de uma só vez, e é a partir da retomada de elementos que já estavam presentes nos primeiros textos em que o autor lida com o otimismo filosófico que Voltaire vai reelaborando suas convicções e dúvidas, chegando a tomar o partido contrário àquele pelo qual se seduzira inicialmente. A análise da pneumatologia de Voltaire ajuda, portanto, a reconhecer o teor negativo de uma personagem como Jesrad, mensageiro de uma sabedoria não humana. Ao invés de Jesrad ser porta-voz da posição do próprio autor no conto, como querem alguns, sua natureza sobrenatural apenas realça as dúvidas do autor quanto à existência de uma providência benevolente.

\section{THE VOLTAIRE'S PNEUMATOLOGY AND THE INTERPRETATION OF ZADIG OR THE DESTINY}

Abstract: The present paper aims at distinguishing two categories of celestial characters found in some Voltaire's texts. The first one concerns the characters coming from the astronomical sky of modern science. The second one could be regarded as the ones which inhabit the ancient heaven of supernatural creatures: angels, genies, and demons. The distinction of these two categories help us to provide an interpretation of Voltaire's Zadig or the destiny and, consequently, comprehend how the author conceived the connections of providence and freedom.

Keywords: Voltaire - celestial beings - sky - heaven - Zadig - destiny - providence - freedom.

\section{REFERÊNCIAS BIBLIOGRÁFICAS}

BARBER, W. H. Leibniz in France from Amauld to Voltaire: A study in French reactions to Leibnizianism, 1670-1760. Oxford: Clarendon Press, 1955.

\footnotetext{
32 A nota é a seguinte: “C'est ici que finit le manuscrit qu'on a retrouvé de l'histoire de Zadig. On sait qu'il a essuyé bien d'autres aventures qui ont été fidèlement écrites. On prie MM. les interprètes des langues orientales de les communiquer si elles parviennent jusqu'à eux". Apud. VAN DEN HEUVEL, Voltaire dans ses contes: de "Micromégas" à "L'ingénu", p. 183.

$33 \mathrm{O}$ abandono do plano providencial põe em evidência a perspectiva particular, sublinhando assim o absurdo da realidade do mal.
} 
BRANDÃO, R. A ordem do mundo e homem: estudos sobre metafísica e moral em Voltaire. Tese de doutorado. Depto. de Filosofia. São Paulo: Universidade de São Paulo, 2009.

- Como levar Cândido a sério ou caricatura literária e crítica da teodiceia em Voltaire. In: Dois pontos, n. 9 (3), pp. 163-179. Curitiba: UFPR/UFSCAR, 2012.

BROOKS, R. A. Voltaire and Leibniæ. Genève: Librairie Droz 1964.

HADOT, P. N'oublie pas de vivre: Goethe et la tradition des exercices spirituels. Paris: Albin Michel, 2008.

KOYRE, A. From the closed world to the infinite universe. Baltimore: Johns Hopkins University Press, 1957.

LEIBNIZ, W. G. Essais de Théodicée. Paris: GF-Flammarion, 1969.

LOCKE, J. An Essay Concerning Human Understanding. Hertfordshire: Wordsworth Classics, 1998.

PELCKMANS, P. Le problème de l'incroyance au XVIIIe siècle. Éditions du CIERL. Québec: Les Presses de l'Université Laval, 2010.

POMEAU, R. La Religion de Voltaire. Paris: Librairie Nizet, 1974.

POMEAU, R. Introduction. In: VOLTAIRE. Micromegas, Zadig, Candide. Paris: GFFlammarion, 1994.

ROVILLAIN, E. Rapports probables entre Zadig de Voltaire et la Pensée Stoïcienne. In: PMLA, Vol. 52. n. ${ }^{\circ}$ 2, pp. 374-389, 1937.

VAN DEN HEUVEL, J. Voltaire dans ses contes: de "Micromégas” à "L'ingénu”. Genève: Slaktine reprints, 1998.

VOLTAIRE. Tratado de Metafísica. Trad. de Marilena Chauí. In: Coleção Os pensadores: Voltaire. São Paulo: Abril Cultural, 1978.

. L’Opinion en Alphabet. In: Oeuvres complètes de Voltaire. Éd. Louis Moland, tome 1720 (1877-1885). Paris: Garnier, 1752.

Contos. Trad. Mário Quintana. São Paulo: Abril Cultural, 1972.

. Discours en vers sur l’homme. In: Mélanges. Paris: Gallimard: 1961.

. Questions sur l'Encyclopédie. In: Collection complètte des oeuvres de M. de Voltaire. Tome 22-23 (1768-1777). Genève: Cramer, 1772. 